\title{
ROLE OF METASTATIC LYMPH NODES TO TOTALLY REMOVED LYMPH NODES RATIO IN BREAST CANCER?
}

\author{
Yasemin Benderli Cihan ${ }^{1}$ \\ ${ }^{1}$ Kayseri Education and Research Hospital, Department of Radiation Oncology, Turkey
}

Received: 14.03.2018.

Accepted: 23.10.2018.

\section{Corresponding author:}

\section{Yasemin Benderli Cihan}

Kayseri Education and Research Hospital, Department of Radiation Oncology, 38010 Kayseri, Turkey

Phone: +90 3523368884

H/P: +90 5362169987

E-mail: cihany@erciyes.edu.tr

\section{sciendo}

UDK: 616.428-033.2-089

618.19-006.6-08

Ser J Exp Clin Res 2022; 23(3):269-273

DOI: $10.2478 /$ sjecr-2018-0070

\begin{abstract}
To determine prognostic ratio of metastatic lymph nodes to totally removed lymph nodes (MLN/TRLN) on overall and progressionfree survival with diagnosis of breast cancer. Radiation Oncology department of Kayseri Training and Research Hospital, relationship of MLN/TRLN between prognosis and other prognostic factors was evaluated in T1-3 and N1-3 non-metastatic breast cancer patients. Two hundred female patients and 5 male patients with an average age of 56 years were enrolled in this study. Of all patients, $63.4 \%$ of the patients were postmenopausal and modified radical mastectomy was performed in $96.6 \%$ of them. While 93.2\% of the patients were diagnosed with invasive ductal carcinoma, $52.7 \%$ of them had clinical N1 disease, $62 \%$ of them were staged as T2, 94\% of them received chemotherapy and 57.1\% of them received hormonal therapy. Metastatic lymph node ratio below 0.2 was $48.8 \%$, between 0.21-0.65 it was 35.1\% and above $0.65 \%$ it was $16.1 \%$. Five-year Overall survival and progressionfree survival rates were $76 \%$ and $58 \%$ respectively. Statistically significant difference was found between MLN/TRLN and age $(p=0.044)$, chemotherapy $(p=0.039)$, pathological lymph nodes $(p<0.001)$ according to Pearson's Chi-Squared test. Factor affecting overall survival was Progesterone receptor status $(p=0.021)$ and for progression-free survival they were gender $(p=0.003)$ and human epidermal growth factor receptor 2 $(p=0.018)$. Univariate and multivariate analysis found that gen$\operatorname{der}(p=0.04$, OR 5.9, CI: 1.7-19.6) and lymph node ( $p=0.05$, OR: 1.4, CI: 0.9-2.1) were significant factors affecting progressionfree survival.

MLN/TRLN was shown to have no effect on prognosis in non-metastatic breast cancer patients due to small number of patients and short follow-up period.
\end{abstract}

Keywords: Breast cancer, metastatic lymph nodes, removed lymph nodes. 


\section{INTRODUCTION}

There have been many studies in the treatment of breast cancer starting from the discovery of anti-cancer drugs and radiotherapy (RT). Given that breast cancer show wide variety of biological difference, heterogeneity and consists of subgroups with different prognosis, there is still no consensus on the optimal treatment. Therefore, in order to individualize treatment, it is required to identify patients with good or poor prognosis $(1,2)$.

While lymph node metastasis is an indicator of poor prognosis, it is still the most powerful prognostic factor for disease-free survival and overall survival. Also axillary lymph node involvement is still considered the most important sign of progressive disease. Therefore axillary lymph node dissection besides providing locoregional control, has huge contribution to accurate staging and to the decision-making process of which patient should be given adjuvant therapy (1-4). In the literature, in cases with node-negative axillary dissection, 5-year survival was reported to be $88 \%$ and 10 -year survival, $65 \%$. In cases with node-positive axillary dissection, when 4 or more axillary lymph node metastases were present, 5 -year survival was reported to be $32 \%$ and 10 -year survival, $13 \%(3)$.

Pathological staging after axillary dissection is gold standard to determine if chemotherapy and/or radiotherapy will be useful. Removal of numerous lymph nodes and excision of metastases provide better prognosis. In many studies, it was observed that number of metastatic lymph nodes were increased in parallel to the number of dissected lymph nodes. In some studies 10 or more dissected lymph nodes, and in some of them 16 and more dissected lymph nodes were shown to represent axillary status in a reliable manner. However, there are reports saying that removal of 4 to 6 lymph nodes with more limited dissection would be enough. Yet, the optimal number of lymph nodes and extension of axillary dissection to provide axillary control and adequate prognostic value haven't been clarified.

Radiotherapy has an important role in the breast cancer treatment. Mastectomy, large tumors, tumors with lymph node metastases and breast-conserving surgery are indications for adjuvant RT. In the treatment planning, target volume is determined by evaluation of patient, tumor, and treatment characteristics. Radiotherapy after mastectomy is often recommended for T3-4 cases with high risk of local recurrence or patients with 4 and more axillary lymph node metastasis. However, in the recent years, patients with 1 to 3 lymph node metastasis have been shown to be sensitive to radiotherapy and it has been increasingly indicated in these patients. Currently the indication for adjuvant RT and determination of RT region are decided according to the number of metastatic lymph nodes (1).

In the recent studies, ratio of metastatic lymph nodes to totally removed lymph nodes (MLR) has been reported to provide better prognostic information while grouping nodal disease according to number of metastatic lymph nodes and making adjuvant treatment plan decisions.

In this study, relationship of MLR between prognosis and other prognostic factors was evaluated in T 1-3 and N 1-3 non-metastatic breast cancer patients. Two hundred female patients and 5 male patients with an average age of 56 years were enrolled in this study. Of all patients, $63.4 \%$ of the patients were postmenopausal and modified radical mastectomy was performed in $96.6 \%$ of them. While $93.2 \%$ of the patients were diagnosed with invasive ductal carcinoma, $52.7 \%$ of them had clinical N1 disease, $62 \%$ of them were staged as T2, 94\% of them received chemotherapy and $57.1 \%$ of them received hormonal therapy. Metastatic lymph node ratio below 0.2 was $48.8 \%$, between $0.21-0.65$ it was $35.1 \%$ and above $0.65 \%$ it was $16.1 \%$.

The median follow-up time was 20 months (range: 1-112 months). Five-year overall survival and progression-free survival rates were $76 \%$ and $58 \%$, respectively. Twenty nine patients died due to either cancer related or other causes. In 43 patients local recurrence or distant metastasis were detected. For age $(p=0.044)$, chemotherapy $(p=0.039)$ and pathological lymph nodes $(\mathrm{p}<0.001)$, statistically significant results were observed with MLR according to Pearson's Chi-Squared test. Factor affecting overall survival was Progesterone receptor status $(\mathrm{p}=0.021)$ and for progression-free survival they were gender $(\mathrm{p}=0.003)$ and human epidermal growth factor receptor $2(\mathrm{p}=0.018)$ (Table 1). According to univariate and multivariate analysis, gender ( $\mathrm{p}=0.04$, OR 5.9, CI: 1.7-19.6) and lymph nodes ( $\mathrm{p}=0.05$, OR: $1.4, \mathrm{CI}$ : 0.9-2.1) were significant factors affecting progression-free survival.

In our study, in the light of literature, the threshold for MLR was taken as 0.20 . Although overall survival and progression-free survival were observed better in patients with MLR of less than 0.2 than in MLR of 0.21-0.65, and above 0.65 , it wasn't statistically significant. When MLR was examined for relation to other parameters, age $(p=0.044)$, chemotherapy $(p=0.039)$ and pathological lymph nodes $(p<0.001)$ were found to be significant. Vinh-Hung et al stated that in node-positive breast cancer patients MLR had prognostic importance and it was an alternative to $\mathrm{pN}$ stage (6). In the meta-analysis of Liu et al, it was reported that in breast cancer patients, MLR had prognostic significance when the threshold (cut-off) values were taken as 0.2 and $0.65(4)$. There are also reports using 0.25 and 0.7 . These differences were mostly result of varied number of patients and treatment modalities (e.g., surgical approach, adjuvant therapy, histological type, size, grade and hormone receptor status of the tumor) $(2,4,5,6)$. In the study of Altundag et al, they evaluated the importance of pathologic node $(\mathrm{pN})$ stages and MLR classification in predicting prognosis. They analyzed N1, N2 and N3 clinical disease by dividing them into subgroups and reported that both $\mathrm{pN}$ stage and MLR classification were independent prognostic factors for overall survival; MLR classification was found to show prognostic distinction for overall survival more accurate and clearer thus it could give more accurate results in both staging and adjuvant 
treatment planning (2). Fortin et al worked with T1-2 stage node-positive patients and suggested axillary radiotherapy to patients who had 1 to 3 lymph nodes metastasis with MLR of 0.4 and above and to patients who had 4 or more lymph node metastasis with MLR above 0.5 (5). In the study of Truong and colleagues which was published in 2005 , they evaluated patients who had no radiotherapy treatment before and who had 1 to 39 lymph nodes removed. Most significant MLR threshold was found as 0.25 to predict locoregional recurrence, distant metastasis and overall survival. Radiotherapy was suggested to patients with MLR more than 0.25 after mastectomy. In 2007, in their other work, to predict locoregional recurrence, they reported that MLR was more significant than $\mathrm{pN}$ stage and also because 10 -year locoregional recurrence risk was above $20 \%$ in patients with MLR more than 0.2 , they recommended radiotherapy to these patients after mastectomy (8).
Karlsson et al found that in node-positive patients who did not receive radiotherapy, with the increase in number of nonmetastatic lymph nodes, locoregional recurrence was significantly reduced and in the group of patients who had 1 to 3 positive lymph nodes and less than 10 non-metastatic lymph nodes, it was indicated that a 10 -year cumulative incidence of locoregional recurrence was over $20 \%$ and these patients should receive post-mastectomy radiotherapy (9).

\section{CONCLUSIONS}

In conclusion, MLR was shown to have no effect on prognosis in non-metastatic breast cancer patients due to small number of patients and short follow-up period. These studies should be supported by more extensive researches to elucidate the role of MLR in prognosis and in adjuvant radiotherapy indication.

Table 1. Overall (OS) and progression-free survival (PFS) and $p$ value $(p<0.05)$

\begin{tabular}{|c|c|c|c|c|c|}
\hline Variable & $\begin{array}{c}\text { No. of } \\
\text { patients }\end{array}$ & $\begin{array}{l}\text { Mean OS } \\
\text { (months) }\end{array}$ & $\begin{array}{c}P \text { value } \\
(<0.05)\end{array}$ & $\begin{array}{c}\text { Mean PFS } \\
\text { (months) }\end{array}$ & $\begin{array}{l}P \text { value } \\
(<0.05)\end{array}$ \\
\hline $\begin{array}{r}\text { male } \\
\text { female }\end{array}$ & $\begin{array}{c}5 \\
201 \\
\end{array}$ & $\begin{array}{r}29.5(29.1-29.7) \\
84.4(73.3-95.4) \\
\end{array}$ & 0.242 & $\begin{array}{c}22.4(14.5-30.3) \\
78.4(69.1-87.6) \\
\end{array}$ & 0.003 \\
\hline Age (years) & $\begin{array}{l}128 \\
77\end{array}$ & $\begin{array}{l}83.5(68.8-98.2) \\
80.1(63.8-94.7)\end{array}$ & 0.885 & $\begin{array}{l}77.2(65.9-88.4) \\
70.7(53.9-87.5)\end{array}$ & 0.988 \\
\hline $\begin{array}{rr}\text { Menopausal status } & \\
& \text { premenopausal } \\
\text { postmenopausa } \\
\text { unknown }\end{array}$ & $\begin{array}{c}68 \\
131 \\
6 \\
\end{array}$ & $\begin{array}{c}65.3(57.1-73.5) \\
83.0(69.8-96.2) \\
- \\
\end{array}$ & 0.804 & $\begin{array}{l}55.3(46.1-64.5) \\
82.1(71.2-39.6) \\
30.2(20.8-39.6) \\
\end{array}$ & 0.318 \\
\hline Performance status & $\begin{array}{c}120 \\
85\end{array}$ & $\begin{array}{c}93.4(83.9-103.0) \\
74.0(72.6-94.7)\end{array}$ & 0.199 & $\begin{array}{l}77.0(64.4-89.6) \\
71.6(57.7-85.5)\end{array}$ & 0.685 \\
\hline $\begin{array}{r}\text { invasive ductal } \\
\text { inflematuar } \\
\text { the other }\end{array}$ & $\begin{array}{c}191 \\
9 \\
5\end{array}$ & $\begin{array}{l}86.2(75.7-96.7) \\
68.3(51.8-84.8) \\
70.9(35.9-1058)\end{array}$ & 0.980 & $\begin{array}{l}78.4(68.8-88.0) \\
56.9(31.1-82.7) \\
54.8(19.9-98.7)\end{array}$ & 0.694 \\
\hline Tumor size & $\begin{array}{c}43 \\
127 \\
35\end{array}$ & $\begin{array}{l}86.9(71.6-102.3) \\
59.3(53.1-65.6) \\
45.6(40.0-51.1)\end{array}$ & 0.883 & $\begin{array}{l}93.3(79.5-107.1) \\
53.1(46.1-60.1) \\
40.5(34.0-47.0)\end{array}$ & 0.147 \\
\hline Lymph node status & $\begin{array}{c}108 \\
51 \\
46 \\
\end{array}$ & $\begin{array}{l}85.2(72.1-98.3) \\
68.1(59.3-76.9) \\
34.3(30.0-38.5) \\
\end{array}$ & 0.275 & $\begin{array}{l}78.3(66.0-90.6) \\
61.6(52.7-70.5) \\
51.1(20.0-82.2) \\
\end{array}$ & 0.079 \\
\hline $\begin{array}{r}\text { I } \\
\text { II } \\
\text { III } \\
\text { unknown } \\
\end{array}$ & $\begin{array}{l}48 \\
90 \\
53 \\
14\end{array}$ & $\begin{array}{l}94.3(78.4-110.2) \\
76.3(63.6-92.1) \\
63.8(52.7-53.5) \\
47.2(38.9-55.4) \\
\end{array}$ & 0.699 & $\begin{array}{c}85.8(69.4-101.5) \\
69.5(57.5-81.4) \\
60.5(48.0-72.9) \\
44.0(34.8-53.1) \\
\end{array}$ & 0.719 \\
\hline Perinodal involvement & 70 & $89.9(73.1-106.8)$ & 0.349 & $76.2(61.2-91.3)$ & 0.676 \\
\hline
\end{tabular}




\begin{tabular}{|c|c|c|c|c|c|}
\hline yes & 135 & $77.2(64.8-89.6)$ & & $74.5(63.8-85.2)$ & \\
\hline Lymphovascular invasion & $\begin{array}{c}87 \\
118\end{array}$ & $\begin{array}{c}94.2(82.7-105.7) \\
66.7(72.6-94.7)\end{array}$ & 0.121 & $\begin{array}{l}72.1(57.7-87.5) \\
65.7(57.7-74.7)\end{array}$ & 0.596 \\
\hline ER status & $\begin{array}{c}120 \\
68 \\
17\end{array}$ & $\begin{array}{l}86.4(74.8-98.0) \\
66.5(58.4-74.6) \\
82.2(72.6-94.7)\end{array}$ & 0.808 & $\begin{array}{l}81.8(70.2-93.4) \\
66.3(55.6-77.1) \\
52.0(29.6-74.5)\end{array}$ & 0.114 \\
\hline $\begin{array}{r}\text { positive } \\
\text { negative } \\
\text { unknown }\end{array}$ & $\begin{array}{c}102 \\
99 \\
4\end{array}$ & $\begin{array}{l}83.0(67.5-98.6) \\
72.1(62.3-81.9) \\
21.6(72.6-94.7)\end{array}$ & 0.021 & $\begin{array}{l}82.2(70.6-93.9) \\
59.6(48.7-70.4) \\
26.2(11.5-40.8)\end{array}$ & 0.484 \\
\hline $\begin{array}{r}\text { negative } \\
\text { positive } \\
\text { unknown }\end{array}$ & $\begin{array}{l}123 \\
65 \\
17\end{array}$ & $\begin{array}{l}88.4(77.0-99.7) \\
47.1(39.2-54.9) \\
68.6(57.2-80.0) \\
\end{array}$ & 0.761 & $\begin{array}{l}86.2(76.2-96.2) \\
39.4(32.2-46.6) \\
68.0(47.6-88.4)\end{array}$ & 0.018 \\
\hline $\begin{array}{r}\text { Number of removed lymph nodes } \\
<16 \\
=>16\end{array}$ & $\begin{array}{l}100 \\
105\end{array}$ & $\begin{array}{l}81.0(69.5-92.5) \\
80.8(72.6-94.7)\end{array}$ & 0.423 & $\begin{array}{l}74.2(61.2-87.2) \\
76.5(64.4-88.6)\end{array}$ & 0.764 \\
\hline $\begin{array}{r}0.0-0.2 \\
0.21-0.65 \\
=>0.65\end{array}$ & $\begin{array}{l}100 \\
72 \\
33\end{array}$ & $\begin{array}{c}83.1(70.2-96.0) \\
82.1(62.9-101.39 \\
57.4(45.3-69.5)\end{array}$ & 0.915 & $\begin{array}{l}77.5(64.9-90.0) \\
72.9(58.0-87.7) \\
57.2(45.2-69.2)\end{array}$ & 0.526 \\
\hline $\begin{array}{l}\text { mastectomy } \\
\text { lumpectomy }\end{array}$ & $\begin{array}{c}196 \\
9\end{array}$ & $\begin{array}{l}83.5(71.9-95.1) \\
77.5(71.9-95.1)\end{array}$ & 0.273 & $\begin{array}{l}76.2(66.6-85.8) \\
75.5(62.9-88.0)\end{array}$ & 0.234 \\
\hline Chemotherapy & $\begin{array}{c}193 \\
12\end{array}$ & $\begin{array}{l}86.1(75.3-96.9) \\
60.2(36.7-83.7)\end{array}$ & 0.307 & $\begin{array}{l}75.8(65.9-85.7) \\
58.4(30.7-86.3)\end{array}$ & 0.610 \\
\hline Hormonotherapy & $\begin{array}{l}117 \\
88\end{array}$ & $\begin{array}{l}86.0(71.8-100.1) \\
64.4(55.3-73.5)\end{array}$ & 0.450 & $\begin{array}{l}72.2(60.3-84.1) \\
66.6(57.8-75.3)\end{array}$ & 0.204 \\
\hline
\end{tabular}

\section{ABBREVIATIONS}

ECOG: Eastern Cooperative Oncology Group;

MLR: metastatic lymph nodes to totally removed lymph nodes ratio;

$\mathbf{N}$ : lymph node;

OS : overall survival;

PFS : progression-free survival;

$\mathbf{T}$ : tumor size.

\section{CONFLICT OF INTERESTS}

The authors declare no conflicts of interest.

\section{FUNDING}

None. 


\section{REFERENCES}

1. Cihan YB. Significance of ABO-Rh blood groups in response and prognosis in breast cancer patients treated with radiotherapy and chemotherapy. Asian Pac J Cancer Prev. 2014;15(9):4055-60.

2. Solak M, Turkoz FP, Keskin O, Aksoy S, Babacan T, Sarici F, et al. The lymph node ratio as an independent prognostic factor for non metastatic node-positive breast cancer recurrence and mortality. J BUON. 2015; 20:73745.

3. Fisher B, Redmond C, Wickerham DL, Wolmark N, Bowman D, Couture J, et al. Systemic therapy in patients with node-negative breast cancer: a commentary based on two National Surgical Adjuvant Breast and Bowel Project (NSABP) clinical trials. Ann Intern Med. 1989;111(9):703-12.

4. Liu D, Chen Y, Deng M, Xie G, Wang J, Zhang L, et al. Lymph node ratio and breast cancer prognosis: a metaanalysis. Breast Cancer. 2014;21(1):1-9.

5. Fortin A, Dagnault A, Blondeau L, Vu TT, Larochelle $M$. The impact of the number of excised axillary nodes and of the percentage of involved nodes on regional nodal failure in patients treated by breast-conserving surgery with or without regional irradiation. Int J Radiat Oncol Biol Phys. 2006;65(1):33-9.
6. Vinh-Hung V, Verkooijen HM, Fioretta G, NeyroudCaspar I, Rapiti E, Vlastos G, et al. Lymph node ratio as an alternative to $\mathrm{pN}$ staging in node-positive breast cancer. J Clin Oncol. 2009;27(7):1062-8.

7. Wu SG, Chen Y, Sun JY, Li FY, Lin Q, Lin HX, et al. Using the lymph nodal ratio to predict the risk of locoregional recurrence in lymph node-positive breast cancer patients treated with mastectomy without radiation therapy. Radiat Oncol. 2013;8:119.

8. Truong PT, Woodward WA, Thames HD, Ragaz J, Olivotto IA, Buchholz TA. The ratio of positive to excised nodes identifies high-risk subsets and reduces inter-institutional differences in locoregional recurrence risk estimates in breast cancer patients with 1-3 positive nodes: an analysis of prospective data from British Columbia and the MD Anderson Cancer Center. Int J Radiat Oncol Biol Phys. 2007;68(1):59-65.

9. Karlsson P, Cole BF, Price KN, Coates AS, CastiglioneGertsch M, Gusterson BA, et al. The role of the number of uninvolved lymph nodes in predicting locoregional recurrence in breast cancer. J Clin Oncol. 2007;25(15): 2019-26. 